Check for updates

Cite this: RSC Adv., 2018, 8, 23529

\title{
The utilization of a stable 2D bilayer MOF for simultaneous study of luminescent and photocatalytic properties: experimental studies and theoretical analysis $\dagger$
}

\author{
Xiren Wu, $\$^{\mathrm{a}}$ Xin Shen, $\$^{\mathrm{a}}$ Shuran Fan, ${ }^{a}$ Manoj Trivedi, (DD ${ }^{\mathrm{b}}$ Boahong Li, \\ Abhinav Kumar (iD) *c and Jianqiang Liu (D) *a
}

\begin{abstract}
A new $\mathrm{Pb}(I)$-based 2D MOF comprising $\pi$-conjugated ligand $44^{\prime}$-(1H-tetrazol-5-yl)-[1,1'-biphenyl]-3,5dicarboxylic acid (TZBPDC) and having the formula $\left\{[\mathrm{PbNa}(\mathrm{TZBPDC})]\left(\mathrm{H}_{2} \mathrm{O}\right)(\mathrm{DMF})_{2}\right\}_{n}$ (1) has been synthesized. Structural characterization of 1 indicates that the MOF has a 4 -connected $(4,4)$ motif. The photoluminescent investigation indicates that 1 can behave as potential luminescent sensor for the detection of nitroaromatic compounds (NACs), especially 2,4-dinitrophenol (2,4-DNP) and ferric ions, through the decrease in its luminescence intensity. Additionally, 1 also displays excellent capacity for the photodegradation of methylene orange (MO), which is a constituent of wastewater discharge. The most plausible mechanisms for the decrease in the luminescent intensity of 1 in the presence of different NACs have been explored though theoretical calculations, and the photocatalysis of 1 for organic dyes has been addressed using density of states (DOS) and partial DOS calculations.
\end{abstract}

Received 15th May 2018

Accepted 12th June 2018

DOI: $10.1039 / \mathrm{c} 8 \mathrm{ra} 04145 \mathrm{~h}$

rsc.li/rsc-advances material scientists trying to seek multi-aperture features. The rational selection of metal ions and ligands in the syntheses of MOFs is very essential to synthesize MOFs that can deliver high stability and outstanding crystallinity. ${ }^{8-11}$

Organic ligands often contain aromatic or conjugated $\pi$ moieties; when they are subjected to excitation through irradiation, they can give rise to optical emissions or photoluminescence. In addition, the metal components, especially lanthanides or $\mathrm{d}^{10}$-metals, can also contribute towards photoluminescence. ${ }^{9}$ Moreover, some studies have established MOFs as photocatalysts, co-catalysts, and hosts for photo-redox catalysis in accordance with their different functions in the photocatalytic systems. The application of MOFs for the photocatalytic degradation of organic pollutants has been thoroughly reviewed, and it has now been established that the photocatalysis in MOFs emerges because of the presence of catalytically active metals and/or functional organic linkers. ${ }^{11}$ Thus, the rational selection of metal ions and ligands in the syntheses of MOFs is of great importance to afford MOFs that can offer good stability, thus ensuring unaltered structures during applications. ${ }^{9}$

Considering the above-mentioned concerns, we have chosen $4^{\prime}$-(1H-tetrazol-5-yl)-[1,1'-biphenyl]-3,5-dicarboxylic acid $\left(\mathrm{H}_{3^{-}}\right.$ TZBPDC) as a ligand, which is an effective building block for three main reasons: (1) it displays many potential coordination modes (Scheme 1), ${ }^{12}$ thereby allowing a platform for the construction of diverse materials; (2) its backbone involves both soft and hard coordination sites (tetrazole and carboxylic acid, \footnotetext{
Laboratory of Research and Development of New Medical Materials of Guangdong Medical University, School of Pharmacy, Guangdong Medical University, Dongguan, +86-29-22896561; Tel: +86-29-22896561

${ }^{b}$ Department of Chemistry, University of Delhi, Delhi, India

'Department of Chemistry, Faculty of Science, University of Lucknow, Lucknow 226 007, India. E-mail: abhinavmarshal@gmail.com

$\dagger$ Electronic supplementary information (ESI) available. CCDC 1832866. For ESI and crystallographic data in CIF or other electronic format see DOI: $10.1039 / \mathrm{c} 8 \mathrm{ra04145h}$

\$ The authors have the equal contributions on this work.
} 
(a)

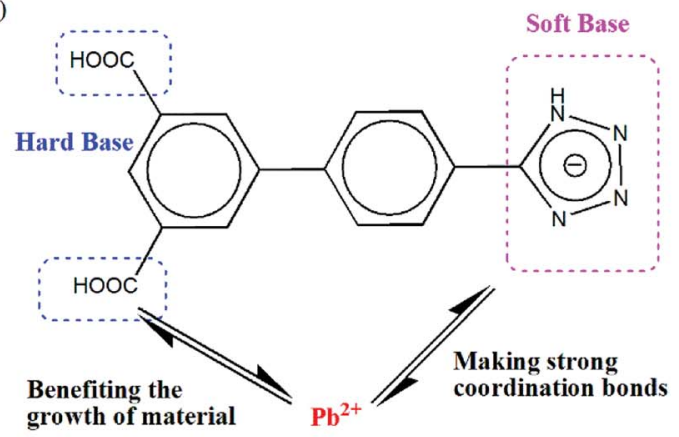

(b)

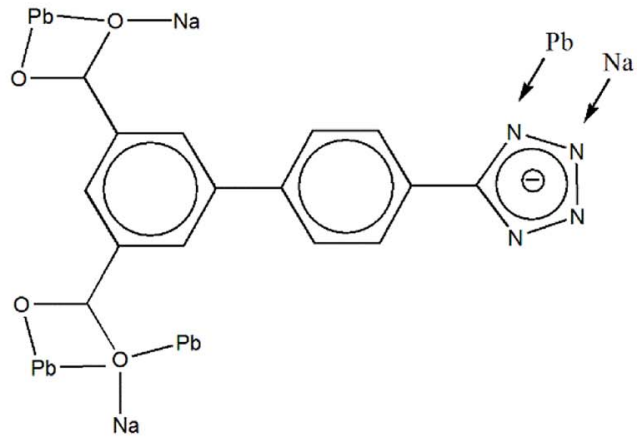

Scheme 1 (a) Illustration for the rational design of $\mathrm{Pb}^{2+}$-based materials, (b) the coordination modes of the ligand involving carboxylate and tetrazole groups.

respectively), which may form much stronger metal-N bonds than metal-O bonds; (3) the electron-rich $\pi$-conjugated backbone can shift the absorption wavelength and promote charge transfer interactions of the resulting architecture, which is promising for the development of luminescent probes and visible-light photocatalysts (Scheme 1). ${ }^{13,14}$

Keeping the aforementioned points in mind and in our continuous quest for the development of functionalized MOFs,${ }^{15}$ we are reporting herein a new $2 \mathrm{D} \mathrm{Pb}^{2+}$-based MOF $\left\{[\mathrm{PbNa}(\mathrm{TZBPDC})]\left(\mathrm{H}_{2} \mathrm{O}\right)(\mathrm{DMF})_{2}\right\}_{n}$ (1), which has been synthesized under hydrothermal conditions. The MOF 1 has been used as a potential luminescent sensor for the detection of nitroaromatics as well as $\mathrm{Fe}^{3+}$ ions. Additionally, the photocatalytic activity of $\mathbf{1}$ for dye degradation under UV-light irradiation has been studied. The results of these investigations are presented herein.

\section{Materials and method}

\section{General considerations}

All chemicals were obtained from commercial sources and used without further purification. Powder X-ray diffraction (PXRD) data were collected on a Bruker D8 ADVANCE X-ray diffractometer equipped with $\mathrm{Cu}-\mathrm{K} \alpha$ radiation $(\lambda=1.5418 \AA)$ at $50 \mathrm{kV}$, $20 \mathrm{~mA}$ with a scanning rate of $6^{\circ} \mathrm{min}^{-1}$ and a step size of $0.02^{\circ}$. The simulated powder patterns for $\mathbf{1}$ were obtained using Mercury 2.0. Samples were formed as KBr pellets, and Fourier transform infrared (FT-IR) spectra were recorded using Nicolet Impact 750 FTIR in the range of $400-4000 \mathrm{~cm}^{-1}$. The thermogravimetric analysis (TGA) was performed under nitrogen atmosphere from room temperature to $650{ }^{\circ} \mathrm{C}$ at a heating rate of $10{ }^{\circ} \mathrm{C} \mathrm{min}^{-1}$ using a SDT Q600 thermogravimetric analyzer.

\section{X-ray crystallography}

The single crystal X-ray diffraction data collections were carried out on a Bruker SMART APEX diffractometer equipped with a graphite monochromated Mo-K $\alpha$ radiation $(\lambda=0.71073 \AA)$ by using the $\omega$-scan technique. The intensities against the absorption effects were corrected by using SADABS. The structure was solved by direct method (SHLEXS-2014) and refined using the full-matrix least-squares procedure based on $F^{2}$ (Shelxl-2014). ${ }^{16}$ All hydrogen atoms were generated geometrically and refined isotropically using the riding model. All nonhydrogen atoms were refined with anisotropic displacement parameters. Crystallographic details and selected bond dimensions for $\mathbf{1}$ are listed in Tables S1 and S2. CCDC number: 1832866.†

\section{Synthesis}

$\left\{[\mathrm{PbNa}(\mathrm{TZBPDC})]\left(\mathrm{H}_{2} \mathrm{O}\right)(\mathrm{DMF})_{2}\right\}_{n}$ (1). A mixture of $4^{\prime}$-(1 $1 H$-tetrazol-5-yl)-[1,1'-biphenyl]-3,5-dicarboxylic acid ( $\mathrm{H}_{3}$ TZBPDC) $(0.031 \mathrm{~g}), \mathrm{Pb}\left(\mathrm{NO}_{3}\right)_{2} \cdot 2 \mathrm{H}_{2} \mathrm{O}(0.033 \mathrm{~g}), 8 \mathrm{~mL}$ of DMF and $2 \mathrm{~mL}$ $\mathrm{NaOH}(0.1 \mathrm{M})$ was stirred for $30 \mathrm{~min}$ and then transferred and sealed in a $25 \mathrm{~mL}$ Teflon-lined reactor, which was then heated to $120{ }^{\circ} \mathrm{C}$ for $72 \mathrm{~h}$. The reaction mixture was cooled to room temperature at a rate of $5{ }^{\circ} \mathrm{C} \mathrm{h}^{-1}$. Colorless crystals of 1 were obtained in $62 \%$ yield based on lead. IR: $3548(\mathrm{v}) ; 2348(\mathrm{~m})$; 1662(v); 1611(m); 1553(v); 1434(v); 1360(vs); 005(m); 851(m); 766(v); 714(m); 543(m).

\section{Photoluminescence measurements}

The photoluminescence properties of $\mathbf{1}$ were investigated in $\mathrm{H}_{2} \mathrm{O} / \mathrm{DMF}$ suspensions at room temperature using an RF5301PC spectrofluorophotometer. These suspensions were prepared by adding $5 \mathrm{mg}$ of finely divided 1 into $3 \mathrm{~mL}$ of $\mathrm{H}_{2} \mathrm{O} /$ DMF and then ultrasonicating the mixture for $30 \mathrm{~min}$ before testing.

\section{Photocatalysis}

Fifty $\mathrm{mg}$ of $\mathbf{1}$ was dispersed in $50 \mathrm{~mL}$ aqueous solutions of $\mathrm{MO} /$ $\mathrm{Rh} \mathrm{B}\left(10 \mathrm{mg} \mathrm{L}^{-1}\right)$ under stirring in dark for $30 \mathrm{~min}$ to ensure the establishment of an adsorption-desorption equilibrium. Thereafter, the mixture was exposed to UV irradiation from a $\mathrm{Hg}$ lamp $(250 \mathrm{~W})$ and kept under continuous stirring during irradiation for $100 \mathrm{~min}$. Samples of $5 \mathrm{~mL}$ were taken out every $10 \mathrm{~min}$, and they were collected by centrifugation for analysis by a UV-Vis spectrometer. Additionally, a simple control 
experiment was also performed under similar reaction conditions without the addition of catalyst.

\section{Computational details}

Density functional theory (DFT) calculations were performed to get information about the mechanism related to the decrease in the luminescent intensity of $\mathbf{1}$ in the presence of NACs as well as the photocatalytic properties and to ascertain the nature of the highest occupied molecular orbitals (HOMO) and lowest unoccupied molecular orbitals (LUMO) of different analytes, the ligand $\mathrm{H}_{3}$ TZBPDC and MOF 1 . The geometry optimizations were performed using the B3LYP exchange-correlation functional. ${ }^{17}$ For all atoms except $\mathrm{Pb}$, the $6-31 \mathrm{G}^{* *}$ basis set was used, whereas for $\mathrm{Pb}$, the CEP-121G basis set was employed for geometry optimization. All calculations were performed using the Gaussian 09 programme. ${ }^{18 a}$ GaussSum 3.1 was used to obtain density of state (DOS) plots. ${ }^{\mathbf{1 8 b}}$

\section{Results and discussion}

\section{Crystal structure}

$\left\{[\mathrm{PbNa}(\mathrm{TZBPDC})]\left(\mathrm{H}_{2} \mathbf{O}\right)(\mathrm{DMF})_{2}\right\}_{\boldsymbol{n}}$ (1). The MOF 1 crystallized in the triclinic system with the $P-1$ space group. The molecular structure of 1 revealed a neutral 2D coordination polymer constructed from clusters (Fig. 1a and S1†) linked to each other. Each cluster comprised two ligands, two aqua, and two DMF molecules as well as two $\mathrm{Pb}(\mathrm{II})$ and two $\mathrm{Na}(\mathrm{I})$ centers. The tetrazole fragment of the ligand coordinated with a $\mathrm{Na(I)}$ ion and a $\mathrm{Pb}$ (II) ion, whereas the carboxylate coordinated to $\mathrm{Pb}$ (II) with one $\mathrm{O}$ and another $\mathrm{O}$ adopting $\mu_{2}$ bonding feature to coordinate with $\mathrm{Na}$ (I) and $\mathrm{Pb}$ (II) (Fig. $1 \mathrm{~b}$ and c). Also, each $\mathrm{Na(I)}$ was blocked by three terminal $\mathrm{O}$ atoms from two DMF molecules and one water molecule. The two adjacent carboxylates in the cluster were directed in the same direction; meanwhile, the tetrazole coordinated with two neighboring $\mathrm{N}$ atoms, and the rest of the two N-centers remained uncoordinated. In this bonding mode, the $\mathrm{Pb}$ (II) ions and $\mathrm{Na}$ (I) ions were bridged by TZBPDC ligands to afford a $2 \mathrm{D}$ network constructed by $\mathrm{Pb}-\mathrm{N}$ and $\mathrm{Na}-\mathrm{N}$ bonds (Fig. $1 \mathrm{c}$ and Table $\mathrm{S} 2 \dagger$ ). All the $\mathrm{Pb}-\mathrm{O}$ and $\mathrm{Pb}-\mathrm{N}$ bond distances were within the range reported for $\mathrm{Pb}(\mathrm{II})$-based MOFs (Table $\mathrm{S} 2 \dagger) .{ }^{12 b}$ From the topological viewpoint, the cluster could be simplified into a 4-connected $(4,4)$ motif. Layer-by-layer eclipsed stacking was observed along the $c$ direction in which a $2 \mathrm{D}$ coordination polymer was generated from this cluster via the ligand, which behaved as linker. Further analysis of the structure indicated that pores exist between these layers (Fig. 1c), and

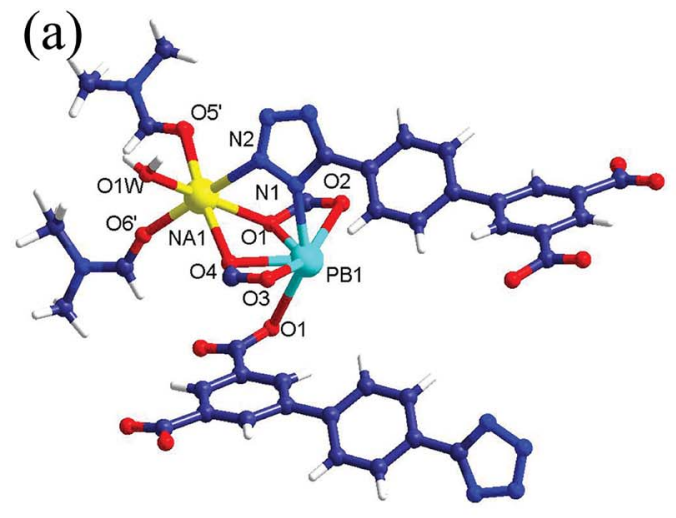

(c)
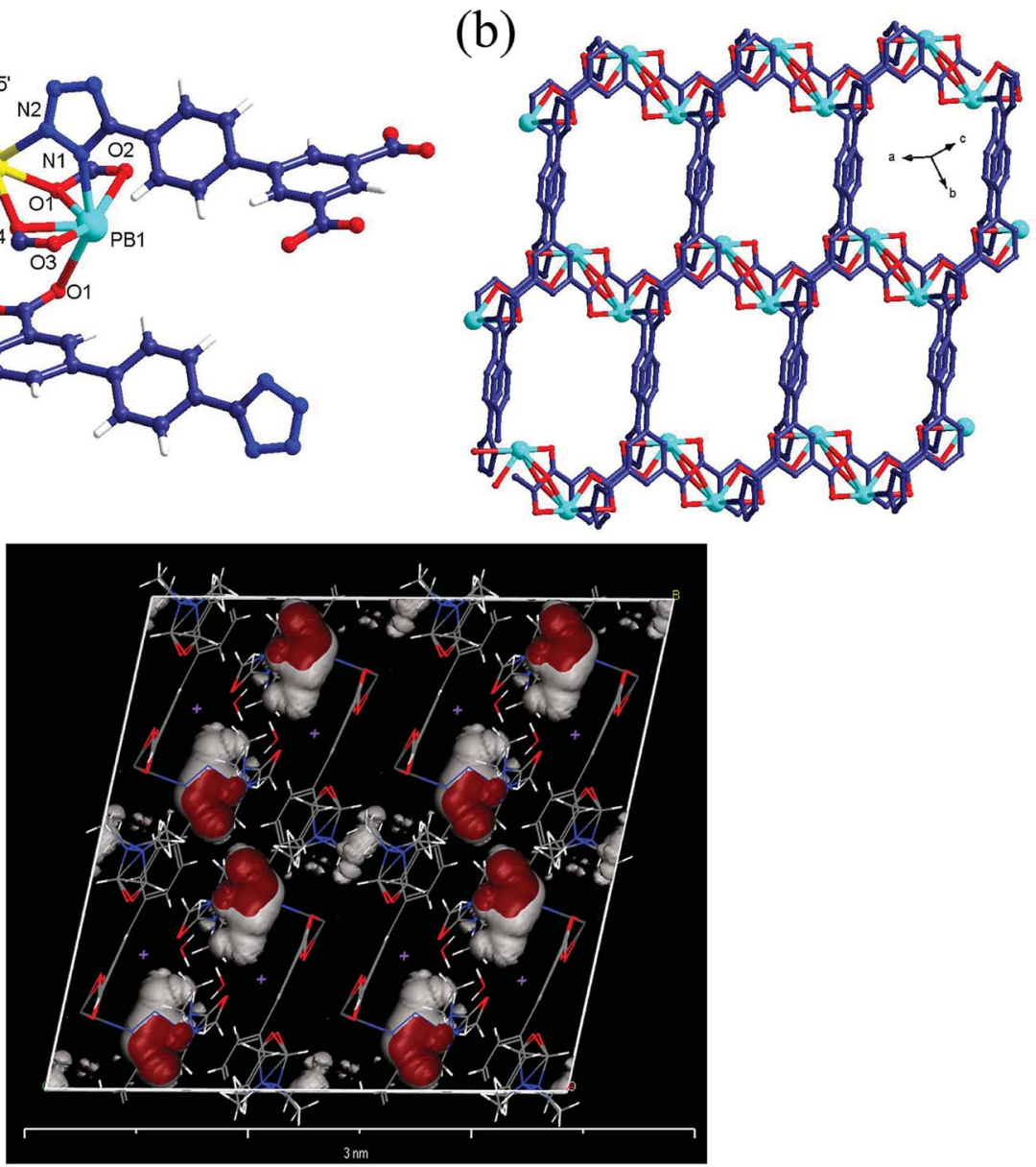

Fig. 1 (a) View of the coordination environments of $\mathrm{Pb}(॥)$ and $\mathrm{Na}($ I) centers; (b) the full 2D bilayer; (c) the pores between the layers. 
the porosity in the MOF was only about $1.2 \%$, which was

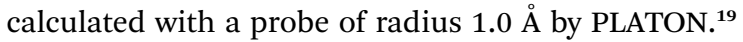

\section{Luminescent sensing}

The purity of 1 was confirmed by similarities between simulated and experimental powder X-ray diffraction (PXRD) patterns (Fig. S2 $\dagger$ ). The thermal stability of $\mathbf{1}$ was also determined by thermogravimetric analysis, which indicated that MOF 1 undergoes gradual weight loss of $22.7 \%$ (calculated $=25.6 \%$ ) up to $335{ }^{\circ} \mathrm{C}$, which corresponds to the loss of $2 \mathrm{DMF}$ and $1 \mathrm{H}_{2} \mathrm{O}$ molecules. The frameworks collapsed at around $400{ }^{\circ} \mathrm{C}$ (Fig. S3†).

Taking into account the excellent luminescent properties of MOFs based on inert pair configuration containing metal centers and $\pi$-conjugated ligands, fluorescences of 1 and $\mathrm{H}_{3}$ TZBPDC ligand were investigated in the solid state (Fig. S4 and $\mathrm{S} 5 \dagger)$. Upon excitation at $\lambda_{\mathrm{ex}}=310 \mathrm{~nm}, 1$ showed strong luminescent emission with maxima at $\lambda_{\mathrm{em}}=460$ (Fig. S5 $\dagger$ ). The weak emission of the $\mathrm{H}_{3}$ TZBPDC ligand was observed at $415 \mathrm{~nm}$ when the ligand was excited at $\lambda_{\mathrm{ex}}=335 \mathrm{~nm}$ (Fig. S4 $\dagger$ ). The emission band for 1 may be due to ligand-to-metal charge transfer (LMCT) ${ }^{20}$ The most significant structural feature of $\mathbf{1}$ is the presence of free Lewis basic sites, due to which it can be a prospective candidate for sensing functions to recognize metal ions. The luminescence spectra of 1 dispersed in aqueous solution containing the same concentrations $\left(10^{-2} \mathrm{M}\right)$ of $\mathrm{M}\left(\mathrm{NO}_{3}\right)_{x}$ were investigated (Fig. 2a and S6 $\dagger$ ). Interestingly, $\mathrm{Fe}^{3+}$ ions displayed significant alleviation effect on the luminescence intensity of $\mathbf{1}$, whereas the $\mathrm{Li}^{+}$and $\mathrm{Na}^{+}$ions exhibited enhancement effect on the luminescence intensity. The unique luminescent alleviation effect of $\mathrm{Fe}^{3+}$ ions in $\mathbf{1}$ was possibly because of the stronger affinity of tetrazole $\mathrm{N}$ atoms of TZBPDC ligand toward $\mathrm{Fe}^{3+}$. This $\mathrm{Fe}^{3+}$-tetrazole interaction reduced the efficiency of energy transfer from TZBPDC linkers to $\mathrm{Pb}^{2+}$ centers, thus decreasing the luminescence intensity. ${ }^{21}$

When the concentration of $\mathrm{Fe}^{3+}$ ions increased in the suspension of $\mathbf{1}$, its luminescent intensity decreased. To explore the sensitivity of $\mathbf{1}$ towards $\mathrm{Fe}^{3+}$ ions, concentration gradient experiments were performed by changing the concentrations of $\mathrm{Fe}^{3+}$ solutions from 0 to 500 ppm (Fig. 2b). It was evident that the luminescence intensities of $\mathrm{Fe}^{3+}$ @1 solutions gradually decreased with the increase in the concentration of $\mathrm{Fe}^{3+}$ ions (Fig. 2b). Furthermore, the fluorescence lifetime of $56.9 \mathrm{~ns}$ for 1 reduced to $5.5 \mathrm{~ns}$ in the presence of $1.0 \mathrm{mM} \mathrm{Fe}^{3+}$ ions (Fig. S7 $\dagger$ ). Hence, it can be concluded that energy transfer may be responsible for the alleviation in the luminescent intensity. Moreover, to elucidate the possible mechanism for luminescence quenching in 1 by $\mathrm{Fe}^{3+}$ ions, O1s and N1s X-ray photoelectron spectroscopy (XPS) studies were carried out on 1 and $\mathrm{Fe}^{3+}$ @1 (Fig. S8-S10†). For 1, the O1s and N1s peaks corresponding to the oxygen atoms of coordinated carboxylate and free nitrogen atoms from tetrazole ring were observed at $531.31 \mathrm{eV}$ and $401.62 \mathrm{eV}$, and these peaks shifted to $532.46 \mathrm{eV}$ and $402.18 \mathrm{eV}$, respectively, upon the addition of $\mathrm{Fe}^{3+}$ (Fig. S8 $\dagger$ ). These slight shifts in the O1s and N1s peaks indicated weak binding of $\mathrm{N} / \mathrm{O}$ centres of $\mathbf{1}$ to $\mathrm{Fe}^{3+}$.
The Stern-Volmer plot for $\mathrm{Fe}^{3+}$ is nearly linear at low concentrations with a $K_{\mathrm{sv}}$ value of $7.67 \times 10^{3} \mathrm{M}^{-1}$ (Fig. 2c), which is comparable to that of the previously reported MOFbased sensors (Table S3†). ${ }^{21}$ On the basis of this plot, the $\mathrm{Fe}^{3+}$ detection limit is calculated to be $1.15 \mathrm{ppm}$. According to the previous reports, ${ }^{22}$ the possible sensing mechanism for luminescence quenching by $\mathrm{Fe}^{3+}$ has been further investigated. To date, several explanations for such quenching effects on luminescence have been explored: (1) the collapse of the framework, ${ }^{22 a-22 d}$ (2) the resonance energy transfer, (3) the weak interaction between metal ions and the heteroatoms within the organic ligands. ${ }^{22 \mathrm{e}, 22 \mathrm{f}}$ Hence, the UV-Vis absorption spectra for $\mathrm{M}\left(\mathrm{NO}_{3}\right)_{x}$ solutions have been recorded (Fig. S12 $\dagger$ ). The UV-Vis spectrum of $\mathrm{Fe}^{3+}$ solution displays significant overlap with the luminescent spectrum of $\mathbf{1}$. Therefore, the competitive absorption of excitation wavelength energy between aqueous $\mathrm{Fe}^{3+}$ solution and $\mathbf{1}$ may also be responsible for the quenching effect. In addition, the luminescence lifetime of $\mathbf{1}$ has a decay time of $5.5 \mathrm{~ns}$, which also indicates that the energy transfer from the ligand to $\mathrm{Pb}$ center has been restrained to a certain extent (Fig. S7†). Finally, the X-ray photoelectron spectroscopy (XPS) experiment on $\mathrm{Fe}^{3+} @ 1$ shows that the typical energy of Fe 2p1 shifts to $779.08 \mathrm{eV}$, resulting in clear increase compared with the standard value, thus demonstrating the interaction between $\mathrm{Fe}^{3+}$ and 1 (Fig. S8-S10†). The powder X-ray diffraction (PXRD) patterns (Fig. S2 $\dagger$ ) indicate possible structural and/or symmetry changes within the crystal structure of $\mathbf{1}$ upon dispersion in the $\mathrm{Fe}^{3+}$ ion solution; notably, these changes are consistent across all metal solutions as well as when $\mathbf{1}$ is soaked in NAC solutions.

The fluorescence response of $\mathbf{1}$ towards small molecules was also examined in DMF suspensions of $\mathbf{1}$ by the addition of different organic molecules. ${ }^{23-25}$ It was observed that NB was able to alleviate the emission of $\mathbf{1}$ effectively (Fig. 3a). The different kinds of aromatic compounds (ACs) used in the investigation were 2,4,6-trinitrophenol (TNP), 2,4-dinitrotoluene (2,4-DNT), 2,6-dinitrotoluene (2,6-DNT), 2-nitrotoluene (2-NT), 4-nitrotoluene (4-NT), 1,3-dinitrobenzene (1,3DNB), 1,2,4-trimethylbenzene (1,2,4-TMB), 1,3,5-trimethylbenzene (1,3,5-TMB), $o$-nitrophenol (ONP), $p$-nitrophenol (PNP), and 2,4-dinitrophenol (2,4-DNP). All the twelve ACs could decrease the luminescent intensity of 1 to a different extent, and the order of quenching efficiency is $2,4-\mathrm{DNP}>\mathrm{NB} \approx 4$-NT $>2,4$ $\mathrm{DNT}>\mathrm{MNP}>2$-NT $>1,3-\mathrm{DNB}>\mathrm{TNP}>2,6-\mathrm{DNT}>1,2,4-\mathrm{TMB}>$ 1,3,5-TMB (Fig. 3b). Furthermore, the fluorescence intensity decreased steadily along with the increase in the concentrations of 2,4-DNP. Additionally, upon the addition of $90 \mathrm{ppm}$ of 2,4DNP, the fluorescence intensity of $\mathbf{1}$ was almost negligible (Fig. 3c). ${ }^{25}$ The absorption spectrum of the 2,4-DNP solution displayed a large overlap with the luminescent spectrum of 1 (Fig. S12†). The emission studies of 1 showed excellent selectivity toward 2,4-DNP, and the addition of 2,4-DNP resulted in quenching of the original emission band and the appearance of a new peak at $480 \mathrm{~nm}$ (Fig. 3c). The emergence of this new peak was observed because 2,4-DNP interacted with the triazole group. This shift/quenching of the emission wavelength might be ascribed to the interaction between 2,4-DNP and 1 and the intramolecular charge-transfer process. Additionally, upon 

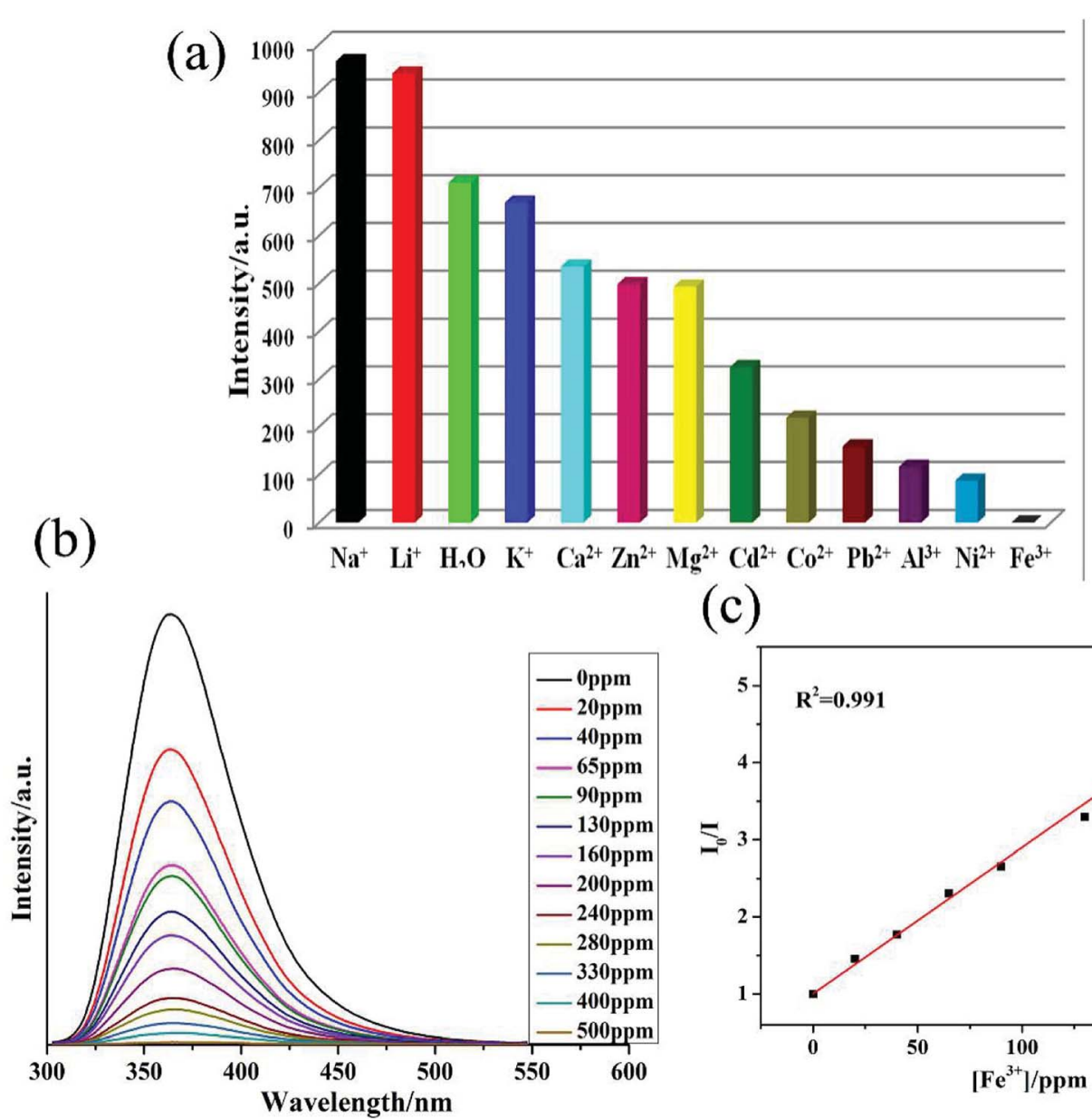

(c)

Fig. 2 (a) Photoluminescence intensity of 1 dispersed in different metal ion solutions; (b) emissive response spectra of 1 for $\mathrm{Fe}^{3+}$ in $\mathrm{H}_{2} \mathrm{O}$ solution with different concentrations; (c) the Stern-Volmer plot for $\mathrm{Fe}^{3+}$.

addition of 1,3,5-TMB and 1,2,4-TMB, the fluorescence intensity of 1 remained almost unaffected (Fig. 3b). However, all other nitro-aromatics showed effects to different extents on the fluorescence intensity of 1 (Fig. $3 \mathrm{~b}$ and S13-S34†). Hence, these results demonstrated that $\mathbf{1}$ possessed selectivity for 2,4-DNP in the presence of different NACs.

The fluorescence quenching efficiency can quantitatively be explained with the help of the Stern-Volmer (SV) equation: $\left(I_{0} / I\right)$ $=1+K_{\mathrm{sv}}[\mathrm{Q}]$. The Stern-Volmer plot for 2,4-DNP is nearly linear at low concentrations with the $K_{\mathrm{sv}}$ value of $1.25 \times 10^{4}$ (Fig. 3d). The 2,4-DNP detection limit is calculated to be $0.88 \mathrm{ppm}$ based on the $3 \delta /$ slope. Therefore, 1 can be used to distinguish NACs having electron-donor and electron-withdrawing substituents. ${ }^{26-28}$ Considering the sizes of NACs and small pores in this MOF, we can neglect the possibility of the accommodation of these analytes in the pores of MOF. The luminescence attenuation in the case of $\mathbf{1}$ can be due to the polarizability of 2,4-DNP and the $\pi-\pi$ interactions between the analytes and the host framework.

The luminescence intensities in the case of $\mathbf{1}$ weakened to different magnitudes when different NACs were added. To explain this decline in the luminescence intensity, the HOMO-
LUMO energies of all the aromatic compounds utilized in this investigation as well as those of $\mathbf{1}$ and the $\mathrm{H}_{3} \mathrm{~L}$ ligand were computed by using the density functional theory (DFT) at the B3LYP level (Table 1, Fig. S37†).

The plausible reason for the decline in luminescence intensity of MOFs after the addition of NACs may be the charge transfer, which takes place from MOF to the LUMO of the aromatic analytes. To facilitate this charge transfer, the LUMO of MOF should have higher energy level in comparison to the LUMOs of the acceptor analytes. ${ }^{29-31}$ As evident from the LUMO energy parameters of $\mathbf{1}$ as well as those of NACs presented in Table 1, the LUMO energy levels for all NACs are low in comparison to those of $\mathbf{1}$ and hence, they can accept charge density from photo-excited 1 . Therefore, this charge transfer results in the decline in luminescence intensity of $\mathbf{1}$ in the presence of these NACs. Furthermore, Table 1 indicates that the aromatic compounds that do not have nitro functions have relatively higher LUMO levels in comparison to $\mathbf{1}$ and hence cannot accept the charge from photo-excited 1 . Therefore, 1,2,4TMB and 1,3,5-TMB have negligible effects on the luminescence intensity of $\mathbf{1}$. However, the observed order of degradation in luminescence intensity of $\mathbf{1}$ by NACs is not in accordance with 

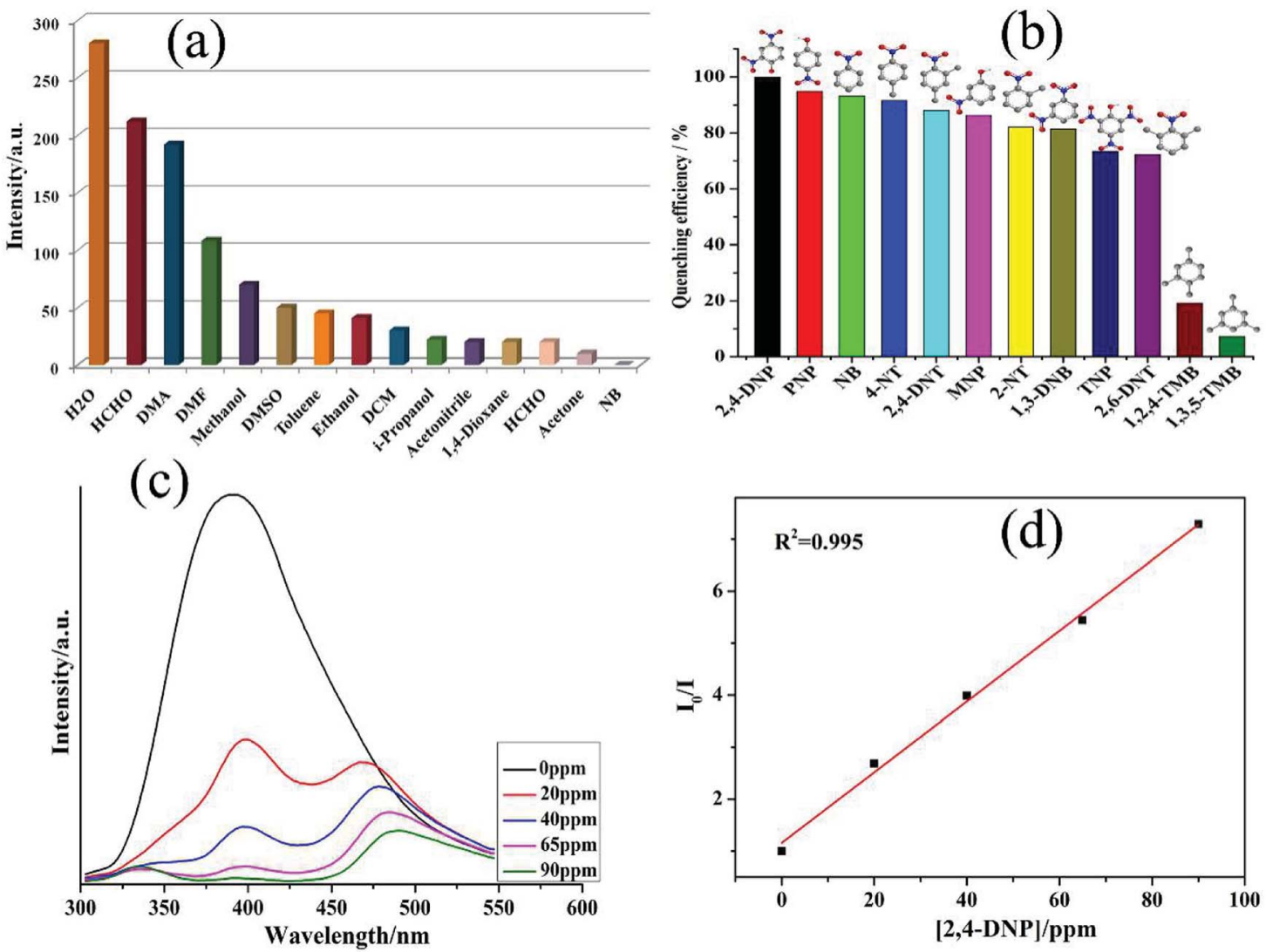

Fig. 3 (a) Photoluminescence intensity of 1 dispersed in different solvents; (b) the order of quenching efficiency of different explosives; (c) emissive response spectra of 1 for 2,4-DNP in DMF solutions; (d) the Stern-Volmer plot for 2,4-DNP.

Table 1 The HOMO-LUMO energies (in eV) for different analytes, ligand and 1

\begin{tabular}{lll}
\hline Ligand/analyte & HOMO & LUMO \\
\hline $\mathrm{H}_{3} \mathrm{~L}$ & -6.45 & -1.81 \\
$\mathbf{1}$ & -2.21 & -1.13 \\
2-Nitrotoluene (2-NT) & -7.28 & -2.32 \\
4-Nitrotoluene (4-NT) & -7.36 & -2.32 \\
Nitrobenzene (NB) & -7.60 & -2.43 \\
2,6-Dinitrotoluene (2,6-DNT) & -7.91 & -2.87 \\
2,4-Dinitrotoluene (2,4-DNT) & -8.11 & -2.98 \\
1,3-Dinitrobenzene (1,3-DNB) & -8.42 & -3.14 \\
2,4,6-Trinitrophenol (TNP) & -8.54 & -3.55 \\
1,2,4-TMB & -6.03 & 0.28 \\
1,3,5-TMB & -6.18 & 0.26 \\
2,4-DNP & -7.62 & -3.33 \\
$o$-Nitrophenol & -6.80 & -2.72 \\
$p$-Nitrophenol & -7.43 & -2.39
\end{tabular}

the corresponding LUMO energy levels of NACs. Hence, charge transfer is not the sole phenomenon responsible for the decline in the luminescence intensity. In addition to electron/energy transfer phenomenon, there may be weak interactions present between 1 and NACs, which contribute to the decrease in the luminescence intensity. ${ }^{27}$ This may be the probable reason that 1,2,4-TMB and 1,3,5-TMB, although having relatively higher LUMO levels than 1, impose some effect on the luminescence intensity of 1. Additionally, there may also be certain constraints related to the transition probability of $\mathbf{1}$; for instance, NACs may inhibit linker motions (in the excited state) in $\mathbf{1}$, which may be responsible for the decline in fluorescence intensity. ${ }^{27 a, b}$

\section{UV-vis diffuse reflectance spectra}

UV-Vis diffuse reflectance spectrum of $\mathbf{1}$ is presented in Fig. $\mathrm{S} 35, \uparrow$ and the spectrum in the form of $R \%$ (reflectance) versus wavelength is shown in Fig. S36. $\dagger 1$ displays broad absorption in the visible region of the electromagnetic spectrum. The band gap of 1 can be determined between the energy axis $(h \nu)$ and the line extrapolated from the linear portion of the adsorption edge in the plots of the Kubelka-Munk function $(F(R))$ versus energy $(h \nu)$. The final result is estimated to be $3.15 \mathrm{eV}$. This wide band gap indicates that $\mathbf{1}$ may behave like a semiconducting material.

\section{Photocatalytic activities}

The presence of visible region transitions motivated us to explore photocatalytic applications of $\mathbf{1}$ toward aromatic dyes, viz., methyl orange (MO) and rhodamine $\mathrm{B}(\mathrm{RhB})$ under UV irradiation. The absorption peaks of $\mathrm{MO}$ and $\mathrm{RhB}$ were found to decrease with an increase in the reaction time with 1 (Fig. 4a and b). The calculated results showed that the conversion rates 

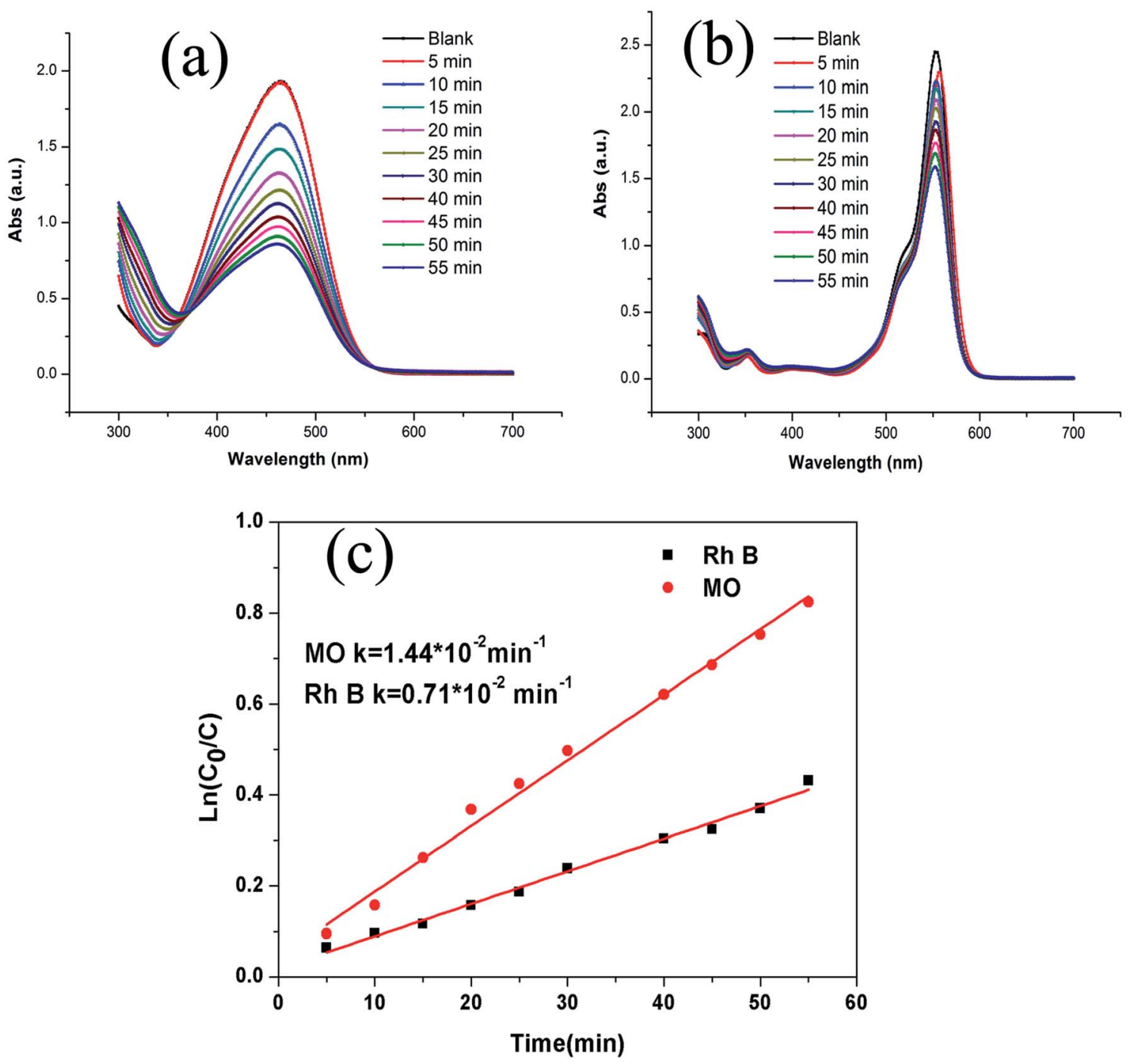

Fig. 4 (a) and (b) UV-vis absorption spectra of the $\mathrm{MO}$ and RhB solutions during the decomposition reaction under $250 \mathrm{~W} H \mathrm{Hg}$ lamp irradiation in the presence of 1, respectively; (c) the plot displaying photocatalytic degradation kinetics of $\mathrm{MO} / \mathrm{RhB}$ with different concentrations of 1.

of $\mathrm{MO}$ and $\mathrm{RhB}$ were $72.8 \%$ and $53.5 \%$, respectively, under UV irradiation. For comparison, the total catalytic degradation efficiency of the control experiment was also explored. The degradation rates of MO and RhB were only $11.9 \%$ and $20.4 \%$, respectively, during 55 min period under the same condition in the absence of the catalyst. The kinetic data for the degradation of MO and RhB could be well fitted by the apparent first-order rate equation, and the rate constants under UV irradiation were found to be $0.0144 \mathrm{~min}^{-1}$ and $0.007 \mathrm{~min}^{-1}$, respectively (Fig. 4c). These results demonstrated that the presence of 1 is necessary for the degradation of MO and RhB. Additionally, the photodegradation of MO in the presence of $\mathbf{1}$ was observed to be much higher than that of RhB. Thus it can be concluded that $\mathbf{1}$ can be chosen as a potential photocatalyst to photodegrade MO. $^{32}$

The plausible photocatalytic degradation mechanisms associated with the organic dyes using the photocatalyst 1 have been addressed with the assistance of band structure calculations for MOF 1. The density of states (DOS) and partial
DOS plots presented in Fig. 5 indicate that the main contribution in valence band, which is present just below the Fermi level, is mainly coming from the carboxylate oxygen and aromatic carbons of TZBPDC moiety with small contributions coming from $\mathrm{Pb}$ (II) and nitrogen centers. Also, the conduction band lying just above the Fermi level in the range of -1.4 to $-0.6 \mathrm{eV}$ is derived from the nitrogen centers of aromatic tetrazole moieties of the TZBPDC ligand. Therefore, the electronic transition in $\mathbf{1}$ mainly takes place from the carboxylate group containing an aromatic center to nitrogen containing tetrazole aromatic region (ligand-to-ligand). On the basis of band structure calculations, it can be inferred that in the photocatalysis step, $\mathbf{1}$ can be excited to produce electron-hole pairs under visible light irradiation; the hole moves to the carboxylate group containing aromatic centers, and the electron migrates to the tetrazole entity. The generation of holes on the carboxylate group containing aromatic centers corresponds to its oxidation; it is now capable of oxidizing the dye to re-reduce back. 


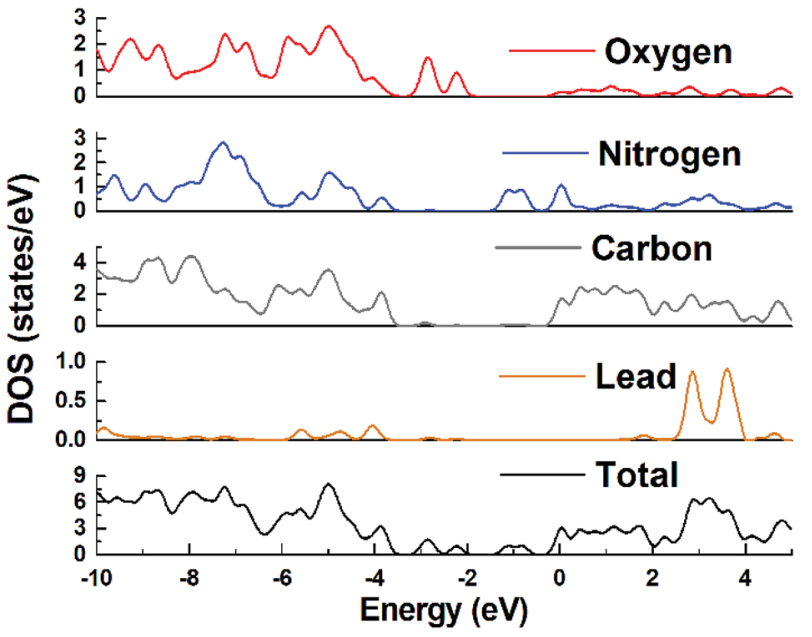

Fig. 5 Density of States (DOS) and partial DOS plots for 1.

\section{Conclusion}

The newly synthesized luminescent $\mathrm{Pb}$ (II)-based MOFs displayed dual sensing properties for the detection of ferric ions and nitro-aromatics, particularly against 2,4-DNP, with low detection limits. Also, 1 displayed photocatalytic degradations of methyl orange and Rhodamine B dyes, and the MOF was capable of photodegrading methyl orange up to $72.8 \%$. The computations based on DFT methods indicated both charge transfer as well as weak interactions operating between $\mathbf{1}$ and NACs, which may be responsible for the decrement in the luminescence intensity of $\mathbf{1}$. Additionally, the DOS calculations revealed that on irradiation, the holes in $\mathbf{1}$ moved to the carboxylate aromatic entity of the ligand, and the electrons moved towards the tetrazole moiety; the generation of holes at these centers induced the oxidation of organic dyes with simultaneous reduction of the hole-containing centers.

\section{Conflicts of interest}

The authors declare no competing conflict of interest.

\section{Acknowledgements}

This work was partially supported by the grants from NSF of China (21701033), Innovative Entrepreneurial Training Plan of undergraduates in Guangdong Province (201710571005, 201710571007; 201710571012; 201710571016; 201710571008; 201710571020, 201710571060) and Innovation experiment project of Guangdong Medical University (ZYDM024), Special Funds for Scientific and Technological Innovation of undergraduates in Guangdong Province (pdjha0218, pdjha0219, pdjha0226), Guangdong Medical university Research Grants (M2015031).

\section{References}

1 (a) J. Guo, J. Yang, Y. Y. Liu and J. F. Ma, CrystEngComm, 2012, 14, 6609-6617; (b) L. L. Wen, L. Zhou, B. G. Zhang, X. G. Meng, H. Qu and D. F. Li, J. Mater. Chem., 2012, 22, 22603-22609; (c) U. Mueller, M. Schubert, F. Teich, H. Puetter, K. Schierle-Arndt and J. Pastre, J. Mater. Chem., 2006, 16, 626-636; (d) J. Y. Lee, O. K. Farha, J. Roberts, K. A. Scheidt, S. B. T. Nguyen and J. T. Hupp, Chem. Soc. Rev., 2009, 38, 1450-1459.

2 (a) J. Y. Sun, L. H. Weng, Y. M. Zhou, J. X. Chen, Z. X. Chen, Z. C. Liu and D. Y. Zhao, Angew. Chem., Int. Ed., 2002, 41, 4471-4473; (b) J. Zhang, Y. Kang, R. B. Zhang, Z. J. Li, J. K. Cheng and Y. G. Yao, CrystEngComm, 2005, 7, 177178; (c) Z. S. Qin, W. W. Dong, J. Zhao, Y. P. Wu, Q. C. Zhang and D. S. Li, Inorg. Chem. Front., 2018, 5, 120126; (d) Z. H. Zhou, W. W. Dong, Y. P. Wu, J. Zhao, D. S. Li, T. Wu and X. H. Bu, Inorg. Chem., 2018, 57, 38333839; (e) Y. P. Wu, W. Zhou, J. Zhao, W. W. Dong, Y. Q. Lan, D. S. Li, C. H. Sun and X. H. Bu, Angew. Chem., Int. Ed., 2018, 56, 13001-13005; (f) L. F. Zou, S. Yao, J. Zhao, D. S. Li, G. H. Li, Q. S. Huo and Y. L. Liu, Cryst. Growth Des., 2017, 17, 3556-3561.

3 (a) J. R. Li, J. Sculley and H. C. Zhou, Chem. Rev., 2012, 112, 869-932; (b) Y. Peng, V. Krungleviciute, I. Eryazici, J. T. Hupp, O. K. Farha and T. Yildirim, J. Am. Chem. Soc., 2013, 135, 11887-11894; (c) Z. Wang and S. M. Cohen, Chem. Soc. Rev., 2009, 38, 1315-1329; (d) J. Pang, F. Jiang, M. Wu, C. Liu, K. Su, W. Lu, D. Yuan and M. Hong, Nat. Commun., 2015, 6, 7575-7581; (e) B. Chen, S. Xiang and G. Qian, Acc. Chem. Res., 2010, 43, 1115-1124.

4 (a) B. Mu, C. X. Li, M. Song, Y. L. Ren and R. D. Huang, CrystEngComm, 2016, 18, 3086-3094; (b) Z. L. Liao, G. D. Li, M. H. Bi and J. S. E. Chen, Inorg. Chem., 2008, 47, 11-13; (c) X. L. Wang, J. J. Huang, L. L. Liu, G. C. Liu, H. Y. Lin, J. W. Zhang, N. L. Chen and Y. Qu, CrystEngComm, 2013, 15, 1960-1969.

5 (a) D. S. Chen, H. Z. Xing, Z. M. Su and C. G. Wang, Chem. Commun., 2016, 52, 2019-2022; (b) T. T. Fan, J. J. Li, X. L. Qu, H. L. Han and X. Li, CrystEngComm, 2015, 17, 9443-9451.

6 (a) H. X. Yang, T. F. Liu, M. N. Cao, H. F. Li, S. Y. Gao and R. Cao, Chem. Commun., 2010, 46, 2429-2431; (b) J. X. Meng, Y. Lu, Y. G. Li, H. Fu and E. B. Wang, CrystEngComm, 2011, 13, 2479-2486; (c) J. Guo, J. Yang, Y. Y. Liu and J. F. Ma, CrystEngComm, 2012, 14, 6609-6617.

7 (a) Q. Huang, J. H. Huang, L. Gu, J. X. Ruan, Y. H. Yu and J. S. Gao, RSC Adv., 2018, 8, 557-566; (b) G. A. Senchyk, A. B. Lysenko, I. Boldog, E. B. Rusanov, A. N. Chernega, H. Krautscheid and K. V. Domasevitch, Dalton Trans., 2012, 41, 8675-8689.

8 (a) J. Zhang, L. Gong, J. Feng, J. Wu and C. Zhang, New J. Chem., 2017, 41, 8107-8117; (b) H. R. Yan, J. Wang, Y. H. Yu, G. F. Hou, H. X. Zhang and J. S. Gao, RSC Adv., 2016, 6, 71206-71213. 
9 Z. Hu, B. J. Deibert and J. Li, Chem. Soc. Rev., 2014, 43, 58155840.

10 (a) M. K. Sharma and P. K. Bharadwaj, Inorg. Chem., 2011, 50, 1889-1897; (b) Y. G. Huang, F. L. Jiang and M. C. Hong, Coord. Chem. Rev., 2009, 253, 2814-2834; (c) F. Wang, Z. S. Liu, H. Yang, Y. X. Tan and J. Zhang, Angew. Chem., Int. Ed., 2011, 50, 450-453.

11 (a) L. L. Wen, F. Wang, J. Feng, K. L. Lv, C. G. Wang and D. F. S. Li, Cryst. Growth Des., 2009, 9, 3581-3589; (b) K. L. Lv and Y. M. Xu, J. Phys. Chem. B, 2006, 110, 62046212; (c) L. L. Wen, J. B. Zhao, K. L. Lv, Y. H. Wu, K. J. Deng, X. K. Leng and D. F. Li, Cryst. Growth Des., 2012, 12, 1603-1612; (d) S. B. Wang and X. C. Wang, Small, 2015, 11, 3097-3112; (e) C. C. Wang, J. R. Li, L. Lv, Y. Q. Zhang and G. Guo, Energy Environ. Sci., 2014, 7, 2831-2850.

12 (a) Y. L. Hu, M. L. Ding, X. Q. Liu, L. B. Sun and H. L. Jiang, Chem. Commun., 2016, 52, 5734-5737; (b) Y. F. Kang, J. Q. Liu, B. Liu, W. T. Zhang, Q. Liu, P. Liu and Y. Y. Wang, Cryst. Growth Des., 2014, 14, 5466-5476.

13 X. Y. Chen, B. Zhao, W. Shi, J. Xia, P. Cheng, D. Z. Liao, S. P. Yan and Z. H. Jiang, Chem. Mater., 2005, 17, 2866-2874. 14 Z. Y. Fu, J. L. Yi, Y. Chen, S. J. Liao, N. Guo, G. D. Yang, Y. X. Lian and X. T. Wu, Eur. J. Inorg. Chem., 2008, 628-634. 15 (a) J. C. Jin, J. Wu, W. C. Liu, A. Q. Ma, J. Q. Liu, A. Singh and A. Kumar, New J. Chem., 2018, 42, 2767-2775; (b) J. Wu, B. H. Li, H. R. Zhong, S. W. Qiu, Y. W. Liang, X. Y. Zhuang, A. Singh and A. Kumar, J. Mol. Struct., 2018, 1158, 264-270; (c) J. Wang, X. R. Wu, J. Q. Liu, B. H. Li, A. Singh, A. Kumar and S. R. Batten, CrystEngComm, 2017, 19, 3519-3525; (d) A. Q. Ma, F. Ke, J. Jiang, Q. Y. Yuan, Z. D. Luo, J. Q. Liu and A. Kumar, CrystEngComm, 2017, 19, 2172-2177; (e) J. Q. Liu, G. L. Liu, C. Y. Gu, W. C. Liu, J. W. Xu, B. H. Li and W. J. Wang, J. Mater. Chem. A, 2016, 4, 11630-11634; (f) J. Q. Liu, Y. Y. Wang, T. Wu and J. Wu, CrystEngComm, 2012, 14, 2906-2913; (g) J. Q. Liu, J. Wu, Y. Y. Wang, J. T. Lin and H. Sakiyama, CrystEngComm, 2014, 16, 3103-3112; (h) J. Q. Liu, J. Wu, Z. B. Jia, H. L. Chen, Q. L. Li, H. Sakiyama, T. Soares, R. Fei, C. Daiguebonne, O. Guillou and S. W. Ng, Dalton Trans., 2014, 43, 17265-17273; (i) L. Lu, J. Wu, J. Wang, J. Q. Liu, B. H. Li, A. Singh, A. Kumar and S. R. Batten, CrystEngComm, 2017, 19, 7057-7067.

16 G. M. Sheldrick, SHELXT - Integrated space-group and crystal-structure determination, Acta Crystallogr., Sect. A: Found. Adv., 2015, 71, 3-8.

17 (a) A. D. Becke, J. Chem. Phys., 1993, 98, 5648-5652; (b) C. T. Lee, W. T. Yang and R. G. Parr, Phys. Rev. B: Condens. Matter Mater. Phys., 1998, 37, 785-789.

18 (a) M. J. Frisch; G. W. Trucks; H. B. Schlegel; G. E. Scuseria; M. A. Robb; J. R. Cheeseman; A. J. Montgomery; T. Vreven Jr; K. N. Kudin; J. C. Burant; J. M. Millam; S. S. Iyengar; J. Tomasi; V. Barone; B. Mennucci; M. Cossi; G. Scalmani; N. Rega; G. A. Petersson; H. Nakatsuji; M. Hada; M. Ehara; K. Toyota; R. Fukuda; J. Hasegawa; M. Ishida; T. Nakajima; Y. Honda; O. Kitao; H. Nakai; M. Klene; X. Li; J. E. Knox; H. P. Hratchian; J. B. Cross; V. Bakken; C. Adamo;
J. Jaramillo; R. Gomperts; R. E. Stratmann; O. Yazyev; A. J. Austin; R. Cammi; C. Pomelli; J. W. Ochterski; P. Y. Ayala; K. Morokuma; G. A. Voth; P. Salvador; J. J. Dannenberg; V. G. Zakrzewski; S. Dapprich; A. D. Daniels; M. C. Strain; O. Farkas; D. K. Malick; A. D. Rabuck; K. Raghavachari; J. B. Foresman; J. V. Ortiz; Q. Cui; A. G. Baboul; S. Clifford; J. Cioslowski; B. B. Stefanov; G. Liu; A. Liashenko; P. Piskorz; I. Komaromi; R. L. Martin; D. J. Fox; T. Keith; M. A. AlLaham; C. Y. Peng; A. Nanayakkara; M. Challacombe; P. M. W. Gill; B. Johnson; W. Chen; W. M. Wong; C. Gonzalez and J. A. PopleGaussian, Inc., Wallingford CT, 2009; (b) N. M. O'Boyle, A. L. Tenderholt and K. M. Langner, J. Comput. Chem., 2008, 29, 839-845.

19 A. L. Spek, J. Appl. Crystallogr., 2003, 36, 7-20.

20 V. Stavila, A. A. Talin and M. D. Allendorf, Chem. Soc. Rev., 2014, 43, 5994-601021.

21 (a) C. Q. Zhang, Y. Yan, Q. H. Pan, L. B. Sun, H. M. He, Y. L. Liu, Y. Z. Q. Liang and J. Y. Li, Dalton Trans., 2015, 44, 13340-13346; (b) D. Wang, L. B. Sun, L. C. Q. Hao, Y. Yan and Z. Q. Liang, RSC Adv., 2016, 6, 57828-57834; (c) J. N. Hao and B. Yan, J. Mater. Chem. C, 2014, 2, 6758-6764. 22 (a) X. Y. Xu and B. Yan, ACS Appl. Mater. Interfaces, 2015, 7, 721-729; (b) S. Dang, E. Ma, Z. M. Sun and H. J. Zhang, J. Mater. Chem., 2012, 22, 16920-16926; (c) Y. Zhou, H. H. Chen and B. Yan, J. Mater. Chem. A, 2014, 2, 1369113697; (d) S. Pramanik, C. Zheng, X. Zhang, T. J. Emge and J. Li, J. Am. Chem. Soc., 2011, 133, 4153-4155; (e) Y. Q. Xiao, Y. J. Cui, Q. A. Zheng, S. C. Xiang, G. D. Qian and B. L. Chen, Chem. Commun., 2010, 46, 5503; $(f)$ B. L. Chen, L. B. Wang, Y. Q. Xiao, F. R. Fronczek, M. Xue, Y. J. Cui and G. D. Qian, Angew. Chem., Int. Ed., 2009, 48, 500. 23 B. Liu, L. Hou, W. P. Wu, A. N. Dou and Y. Y. Wang, Dalton Trans., 2015, 44, 4423-4427.

24 X. W. Yang, Y. Zhang, F. Li, T. T. Guo, Y. Wu, F. Y. Jin, M. Fang, Y. Q. Lan, Y. F. Li, Y. Zhou and Z. G. Zou, Dalton Trans., 2017, 46, 8204-8218.

25 (a) J. Guo, J. F. Ma, B. Liu, W. Q. Kan and J. Yang, Cryst. Growth Des., 2011, 11, 3609-3621; (b) L. Liu, J. Ding, M. Li, X. Lv, J. Wu, H. Hou and Y. Fan, Dalton Trans., 2014, 43, 12790-12799; (c) J. C. Jin, L. Y. Pang, G. P. Yang, L. Hou and Y. Y. Wang, Dalton Trans., 2015, 44, 17222-17228.

26 (a) C. X. Yang, H. B. Ren and X. P. Yan, Anal. Chem., 2013, 85, 7441-7466; (b) S. Xiang, W. Zhou, Z. Zhang, M. A. Green, Y. Liu and B. Chen, Angew. Chem., Int. Ed., 2010, 49, 46154618; (c) J. Wang, Y. Li, M. Jiang, Y. H. Liu, L. W. Zhang and P. Y. Wu, Chem.-Eur. J., 2016, 22, 13023-13027.

27 (a) J. Guo, J. Yang, Y. Y. Liu and J. F. Ma, CrystEngComm, 2012, 14, 6609-6617; (b) Y. Li, H. Xu, S. X. Ouyang and J. H. Ye, Phys. Chem. Chem. Phys., 2016, 18, 7563-7572.

28 (a) L. L. Wen, F. Wang, J. Feng, K. L. Lv, C. G. Wang and D. F. Li, Cryst. Growth Des., 2009, 9, 3581-3589; (b) M. Q. $\mathrm{Hu}$ and Y. M. Xu, Chemosphere, 2004, 54, 431-434; (c) L. L. Wen, J. B. Zhao, K. L. Lv, Y. H. Wu, K. J. Deng, X. K. Leng and D. F. Li, Cryst. Growth Des., 2012, 12, 16031612. 
29 L. L. Zhang, Z. X. Kang, X. L. Xin and D. F. Sun, CrystEngComm, 2016, 18, 193.

30 (a) J. Li, G. P. Yang, L. Hou, L. Cui, Y. P. Li, Y. Y. Wang and Q. Z. Shi, Dalton Trans., 2013, 42, 13590; (b) S. Zhao, J. G. Ding, T. R. Zheng, K. Li, B. L. Li and B. Wu, J. Lumin., 2017, 188, 356.
31 S. Pramanik, C. Zheng, X. Zhang, T. J. Emge and J. Li, J. Am. Chem. Soc., 2011, 133, 4153.

32 (a) A. K. Paul, G. Madras and S. Natarajan, Phys. Chem. Chem. Phys., 2009, 11, 11285; (b) G. S. Yang, H. Y. Zang, Y. Q. Lan, X. L. Wang, C. J. Jiang, Z. M. Su and L. D. Zhu, CrystEngComm, 2011, 13, 1461. 